\title{
Retention of adolescents living with HIV in care, treatment, and support programs in Uganda
}

Livingstone Ssali

Sam Kalibala

Population Council

Josephine Birungi

Aggrey Egessa

Jonathan Wangisi

See next page for additional authors

Follow this and additional works at: https://knowledgecommons.popcouncil.org/departments_sbsr-hiv

Part of the Demography, Population, and Ecology Commons, Family, Life Course, and Society Commons, International Public Health Commons, and the Maternal and Child Health Commons How does access to this work benefit you? Let us know!

\section{Recommended Citation}

Ssali, Livingstone, Sam Kalibala, Josephine Birungi, Aggrey Egessa, Jonathan Wangisi, Joanne Lyavala Okullu, Celestin Bakanda, Stephen Okoboi, and Francis Obare. 2014. "Retention of adolescents living with HIV in care, treatment, and support programs in Uganda." Washington, DC: USAID | Project Search: HIVCore. 


\section{Authors}

Livingstone Ssali, Sam Kalibala, Josephine Birungi, Aggrey Egessa, Jonathan Wangisi, Joanne Lyavala Okullu, Celestin Bakanda, Stephen Okoboi, and Francis Obare 
䨐

PEPFÁR

\section{HIVCore}

\section{RETENTION OF ADOLESCENTS LIVING WITH HIV IN CARE, TREATMENT,AND SUPPORT PROGRAMS IN UGANDA}

22 December 2014

This publication was produced for the United States Agency for International Development. It was prepared by Livingstone Ssali, Sam Kalibala, Josephine Birungi, Aggrey Egessa, Jonathan Wangisi, Lyavala Joanne Okullu, Celestin Bakanda, Stephen Okoboi, and Francis Obare. 



\section{RETENTION OF \\ ADOLESCENTS LIVING WITH HIV IN CARE,TREATMENT, AND SUPPORT PROGRAMS IN UGANDA}

LIVINGSTONE SSALI', SAM KALIBALA², JOSEPHINE BIRUNGI', AGGREY EGESSA', JONATHAN WANGISI', LYAVALA JOANNE OKULLU', CELESTIN BAKANDA', STEPHEN OKOBOI', FRANCIS OBARE $^{3}$

ITHE AIDS SUPPORT ORGANIZATION (TASO), UGANDA ${ }^{2}$ HIVCORE/POPULATION COUNCIL, WASHINGTON, DC, USA ${ }^{3}$ HIVCORE/POPULATION COUNCIL, NAIROBI, KENYA

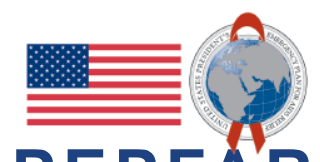

PEPFAR 


\section{ACKNOWLEDGMENTS}

The study was implemented by The AIDS Support Organization (TASO)-Uganda and the Population Council. Andrew Mijumbi of TASO provided valuable administrative support for the study while Norah Omenda of the Population Council provided logistics support for the principal investigator. Data for the study were provided by all TASO centers. The Population Council Institutional Review Board, TASO Institutional Review Committee, and the Uganda National Council for Science and Technology (UNCST) granted ethical approvals for the study.
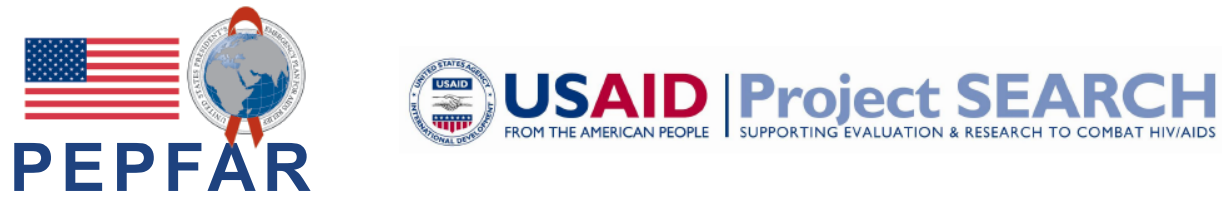

This report was made possible through support provided by the President's Emergency Plan for AIDS Relief and the U.S. Agency for International Development (USAID) via HIVCore, a Task Order funded by USAID under the Project SEARCH indefinite quantity contract (Contract No. AID-OAA-TO-11-00060).

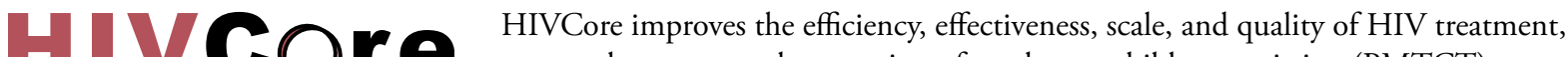 care, and support, and prevention of mother-to-child transmission (PMTCT) programs. The Task Order is led by the Population Council in partnership with the Futures Group, the Elizabeth Glaser Pediatric AIDS Foundation, and the University of Washington.}

Published in December 2014. (02014. The Population Council Inc.

Cover photo credit: Provided courtesty of The AIDS Support Organization (TASO)-Uganda

Suggested citation: Ssali, Livingstone, Sam Kalibala, Josephine Birungi, Aggrey Egessa, Jonathan Wangisi, Lyavala Joanne Okullu, Celestin Bakanda, Stephen Okoboi, and Francis Obare. 2014. "Retention of adolescents living with HIV in care, treatment, and support programs in Uganda," HIVCore Final Report. Washington, DC: USAID | Project Search: HIVCore. 


\section{TABLE OF CONTENTS}

ACRONYMS

EXECUTIVE SUMMARY

INTRODUCTION 4

METHODOLOGY 6

Study design and sample $\quad 6$

$\begin{array}{ll}\text { Review of documents } & 7\end{array}$

$\begin{array}{ll}\text { Extraction of clinical datasets } & 7\end{array}$

$\begin{array}{ll}\text { Data analysis } & 7\end{array}$

$\begin{array}{ll}\text { Ethical considerations } & 8\end{array}$

KEY FINDINGS 9

Characteristics of adolescents 9

Cascade of care under HBHTC program $\quad 11$

Level of retention of adolescents in ART programs $\quad 14$

Trends in retention of adolescents in ART programs $\quad 15$

Factors associated with non-retention of adolescents in ART programs $\quad 15$

CONCLUSIONS AND RECOMMENDATIONS $\quad 18$

Discussion $\quad 18$

$\begin{array}{ll}\text { Conclusion } & 20\end{array}$

$\begin{array}{ll}\text { Recommendations } & 20\end{array}$

REFERENCES

APPENDIX: DOCUMENT REVIEW

$\begin{array}{ll}\text { Policy context } & 24\end{array}$

$\begin{array}{ll}\text { Programmatic context } & 26\end{array}$

$\begin{array}{ll}\text { Summary and implications } & 27\end{array}$ 


\section{ACRONYMS}

$\mathrm{ABC}$

Abstinence, Being faithful, and Condom use

AHR

Adjusted Hazard Ratio

AIC

AIDS Information Center

AIDS

Acquired Immunodeficiency Syndrome

ART

Antiretroviral Treatment

ARV

Antiretroviral

BCC

Behavior Change Communication

CDDP

Community Drug Distribution Point

CHCT

Couple HIV Counseling and Testing

CI

Confidence Interval

CICT

Client-initiated Counseling and Testing

$\mathrm{CSO}$

Civil Society Organization

HBHTC

Home-based HIV Testing and Counseling

HCT

HIV Counseling and Testing

HIV

Human Immunodeficiency Syndrome

IEC

Information, Education and Communication

LTFU

Loss to Follow Up

NGO

Nongovernmental Organization

OVC

Orphans and Vulnerable Children

PITC

Provider-initiated Testing and Counseling

PMTCT

Prevention of Mother-to-child Transmission

SAGE

Social Assistance Grants for Empowerment

SRH

Sexual and Reproductive Health

STI

Sexually Transmitted Infection

TASO

The AIDS Support Organization

UNAIDS

Joint United Nations Programme on HIV/AIDS

UNCST

Uganda National Council for Science and Technology

UNFPA

United Nations Fund for Population Activities

USAID

U.S. Agency for International Development

VCT

Voluntary Counseling and Testing

WHO

World Health Organization 


\section{EXECUTIVE SUMMARY}

In many countries in sub-Saharan Africa, HIV programs are organized around pediatric or adult care, with adolescents who are living with HIV being treated through pediatric care facilities. This has important implications for retention of adolescents in HIV care programs especially as they transition from pediatric to adult care. Although Uganda is considered a success story in HIV/AIDS programming, the extent to which adolescents living with HIV have been retained in care is not well understood. Retention in care is important for positive clinical outcomes such as viral load suppression and survival. The AIDS Support Organization (TASO) and the Population Council undertook a study to generate evidence on the level of and the factors associated with retention of adolescents aged 10-19 years in HIV and AIDS programs in Uganda. The study was conducted under the U.S. Agency for International Development's (USAID) HIVCore project led by the Population Council. The study specifically examined: (1) the contextual factors that might facilitate or influence retention of adolescents in HIV care, treatment, and support services in Uganda; (2) the cascade of HIV care, treatment, and support services among adolescents aged 10-19 years in Uganda and how these patterns compare with those of adults aged 20 years and above; (3) the level of and trends in retention in care, treatment, and support programs among adolescents aged 10-19 years in the country in the context of current HIV and AIDS programs at $6,12,24,36$, and 48 months following initiation of antiretroviral therapy (ART); and (4) the sociodemographic characteristics that are associated with retention in HIV care, treatment, and support programs among adolescents in Uganda at three different follow-up periods (12, 24, and 36 months).

The study reviewed existing national policy and program documents on HIV testing, counseling, treatment, and support as well as retrospective secondary cohort clinical data from clinics operated by TASO in Uganda. TASO implements several HIV-related activities including prevention, counseling, testing, treatment, care, and support services as well as capacity development, research, and advocacy. The study population for the clinical component comprised: (1) 22,089 adolescents aged 10-19 years and 33,139 adults aged 20 years and above who received HIV services under the home-based HIV testing and counseling (HBHTC) program from 2005 (when TASO initiated the program) to 2011; and (2) clinical records of 617 adolescent clients aged 10-19 years (at the time of enrollment) who received HIV care, treatment, and support services from TASO clinics between 2006 and 2011. The review of policy and program documents as well as the extraction and merging of clinical datasets took place from 4-15 November 2013. The HBHTC and ART datasets were obtained from 11 TASO centers. The ART datasets were extracted from the following records: Pre-ART Registry, Case Evaluation, ART Commencement, Deaths, Monitoring Refills, and Laboratory. We identified a patient cohort within the TASO Management Information System who initiated ART since 2006. Analysis involved both descriptive statistics and multivariate Cox regression analysis. Descriptive analysis entailed reviewing the cascade of HIV care, treatment, and support services under the HBHTC program as well as estimating the level of retention in TASO ART programs at 6, 12, 24, 36, and 48 months. Multivariate Cox regression analysis was conducted to determine the sociodemographic and clinical factors associated with program attrition at 12,24 , and 36 months. 


\section{KEY FINDINGS}

- The HBHTC program contributed to increasing proportions of adolescents aged 10-19 years being enrolled in TASO care centers during the first four years of its operation. In particular, among the adolescents who tested HIV positive in TASO's HBHTC programs, the proportion that was enrolled in TASO centers more than quadrupled from 9 percent in 2005 to 41 percent in 2008. However, that proportion declined thereafter by about half to 20 percent by 2010 .

- The overall level of retention of adolescents in TASO ART programs was 96 percent at 6 months, 90 percent at 12 months, 83 percent at 24 months, 76 percent at 36 months, and 71 percent at 48 months, which is comparable with those of adults in existing studies. However, there were variations in the level of retention of various cohorts of adolescents especially from 12 months onwards. Specifically, retention at each time period decreased among adolescents initiating ART in each successive year after 2006 and the gaps widened with longer duration of observation. The high levels of retention of adolescents in TASO treatment programs could, however, be due to the intensive resources geared towards targeting whole families with HIV testing, counseling, treatment, and support services. Thus, although resources for targeting whole families may not always be available, the programs provide valuable lessons for improving access to treatment services for HIV-positive adolescents.

- The risk of non-retention of adolescents in TASO programs was significantly greater among those who obtained their antiretroviral (ARV) drug refills from a health facility than among those who obtained the refills from community drug distribution points at all the time points considered $(12,24$, and 36 months). In addition, the risk of non-retention in care was significantly greater among adolescents at WHO clinical stage 3 and 4 than among those at stage 1 and 2 at 12 months. The findings suggest that community-based ART distribution initiatives and early diagnosis of HIV infection do improve the chances of retaining adolescents in ART programs. Variations in the risk of non-retention in treatment programs by venue of drug refills could be due to most adolescents receiving drugs from community drug distribution points being those with high levels of adherence. A cross-tabulation of adherence level and venue of drug refill though, showed that there was no significant association between the two attributes, suggesting that counseling and close monitoring might have improved adherence among clients who received drug refills from facilities.

- The risk of non-retention in care was significantly greater among older (15-19 years) than among younger (10-14 years) adolescents at 12 and 24 months. In addition, at 24 and 36 months, the risk of non-retention in care was significantly greater among adolescents with higher than among those with lower CD4 count at the time of initiating ART.

- Contrary to existing literature (Braitstein et al. 2008) which indicates that females are better at seeking healthcare than males, the results of this study showed that with longer duration of observation (at 24 and 36 months), the risk of non-retention in care was significantly lower among male compared to female adolescents.

\section{RECOMMENDATIONS}

- HIV care, treatment, and support programs in Uganda should strengthen such strategies as community drug distribution points, which have the potential to improve retention of adolescents in care and treatment, to specifically target those who are at high risk of dropping out.

- Further research is needed to determine whether setting up transition units to cater to older adolescents who receive services from health facilities but are not comfortable with obtaining services from pediatric or adult clinics could improve retention among adolescents. 
- Further research involving collection of primary quantitative and qualitative data is needed to determine why later cohorts of adolescents had lower levels of retention in care compared to earlier cohorts and why male adolescents had significantly lower risk of non-retention in care compared to their female counterparts. 


\section{INTRODUCTION}

Globally, the number of children aged under 15 years who were living with HIV increased from 2.0 million in 2001 to 2.5 million by the end of 2010 (UNAIDS 2010a). Most of these children (90 percent) were in sub-Saharan Africa, where the number increased from 1.8 million to 2.3 million over the same period (UNAIDS 2010a). New infections and the expansion of antiretroviral treatment (ART) contributed to the increased number of children living with HIV (UNAIDS 2011). In Uganda, for instance, it was estimated that 190,000 children aged under 15 years were living with HIV as of 2011, while 21,000 new infections occurred among this age group in that year (UNAIDS 2012). The implication is that increasing numbers of children infected with HIV in sub-Saharan Africa mature into adolescence and adulthood. As with most adolescents, many of these young people become sexually active and even have children (Birungi et al. 2008, 2011). Moreover, many adolescents who were not born with HIV become sexually active and expose themselves to the risk of HIV infection by not or inconsistently using preventive methods (Hindin and Fatusi 2009). In Uganda, for example, estimates show that HIV prevalence among adolescents aged $15-19$ years is 2.4 percent (3.0 percent and 1.7 percent among adolescent girls and boys respectively) (Ministry of Health et al. 2012).

Yet, in many countries in sub-Saharan Africa, HIV programs are organized around pediatric or adult care with adolescents who are living with HIV being treated through pediatric care facilities. Such facilities are ill-equipped to provide adolescents with the information they need to deal with sexual and reproductive health (SRH) issues of concern to them. For example, available evidence from Kenya and Uganda shows that the majority of adolescents who are living with HIV are very worried about becoming pregnant or impregnating someone, disclosing their HIV status, and infecting others and re-infecting themselves; yet their preventive practices are just as poor as among adolescents in general (Birungi et al. 2008, 2011). Moreover, existing counseling services for adolescents have not provided pragmatic solutions for those who are sexually active beyond emphasizing that they should refrain from sexual activity, which in most cases is not heeded (Birungi et al. 2008). Evidence from Uganda further shows that many adolescent girls disappear from HIV and AIDS programs once they become pregnant and it is obvious that they did not heed the counselors' advice to refrain from sexual activity (Birungi et al. 2009).

The gaps in HIV and AIDS programming for adolescents living with HIV have important implications for retention of this age group in HIV care, treatment, and support programs as well as for adherence to treatment, especially as they transition from pediatric to adult clinics. For example, available evidence indicates that in low-resource settings, adherence to treatment is generally poorer among adolescents compared to children or adults (Foster and Fidler 2010). Moreover, although Uganda has been considered a success story in HIV and AIDS programming that contributed to substantial declines in HIV prevalence over time (Ministry of Health et al. 2012), there has been little consideration of the extent to which the country has succeeded in retaining HIV-positive adolescents aged 10-19 years in such programs given the challenges faced by this subset of the population regarding adherence as well as transition from pediatric to adult care. This raises some important research questions:

1. What is the level of retention in HIV and AIDS programs among HIV-positive adolescents aged 10-19 years in the country? 
2. Are HIV-positive adolescent clients who remain in HIV and AIDS programs different from those who drop out in terms of sociodemographic characteristics?

Understanding the extent to which adolescents aged 10-19 years who are living with HIV are retained in HIV care, treatment, and support is important for informing the design of effective comprehensive services for this subset of the population in order to better meet their needs across three main areas of HIV and AIDS programming: treatment; care and support; and prevention. Effective, comprehensive services that benefit adolescents and contribute towards their retention in HIV care, treatment, and support programs are a pressing priority for the national AIDS control programs in many countries affected by the epidemic. Retention in HIV programs is, in turn, important for positive clinical outcomes including viral suppression and survival (Giordano 2012; Giordano et al. 2007; WHO 2012).

In 2013-2014, The AIDS Support Organization (TASO) and the Population Council undertook a study to generate evidence on the level of and the factors associated with retention of adolescents aged 10-19 years in HIV and AIDS programs in Uganda. The study was conducted under the U.S. Agency for International Development's (USAID) HIVCore project led by the Population Council. The study further responds to the guidelines by the World Health Organization (WHO) and the United Nations Fund for Population Activities (UNFPA) on care, treatment, and support for women living with HIV and AIDS and their children in resource-constrained settings that emphasize ensuring the availability of ageappropriate information and counseling on SRH and safer sexual practices, and offering family planning counseling and services that are adolescent-friendly (WHO and UNFPA 2006).

The goal of the study was to generate evidence on the level of and the factors associated with retention of HIV-positive adolescents aged 10-19 years in HIV and AIDS programs in Uganda. The specific objectives of the study were to:

1. Examine the contextual factors that might facilitate or influence retention of adolescents in HIV care, treatment, and support services in Uganda.

2. Examine the cascade of HIV care, treatment, and support services among adolescents aged 10-19 years in Uganda and how these patterns compare with those of adults aged 20 years and above.

3. Examine the level of and trend in retention in care, treatment, and support programs among adolescents aged 10-19 years in the country in the context of current HIV and AIDS programs at 6, $12,24,36$, and 48 months following initiation of ART.

4. Assess the sociodemographic characteristics and clinical factors that are associated with retention in HIV care, treatment, and support programs among adolescents in Uganda at three different follow-up periods (12, 24, and 36 months). 


\section{METHODOLOGY}

\section{STUDY DESIGN AND SAMPLE}

The study used existing national policy and program documents on HIV testing, counseling, treatment, and support as well as retrospective secondary cohort clinical data from 11 clinics operated by TASO in Uganda. The study population for the clinical component comprised:

1. 22,089 adolescents aged 10-19 years and 33,139 adults aged 20 years and above regardless of HIV status who received HIV services under the home-based HIV testing and counseling (HBHTC) program from 2005 (when TASO initiated the program) to 2011.

2. Clinical records of $617 \mathrm{HIV}$-positive adolescent clients aged 10-19 years (at the time of enrollment) who received HIV care, treatment, and support services from TASO clinics between 2006 and 2011.

The steps in sample selection for each of the study populations are summarized in Figure 1.

Figure I Flow chart showing steps in sample selection

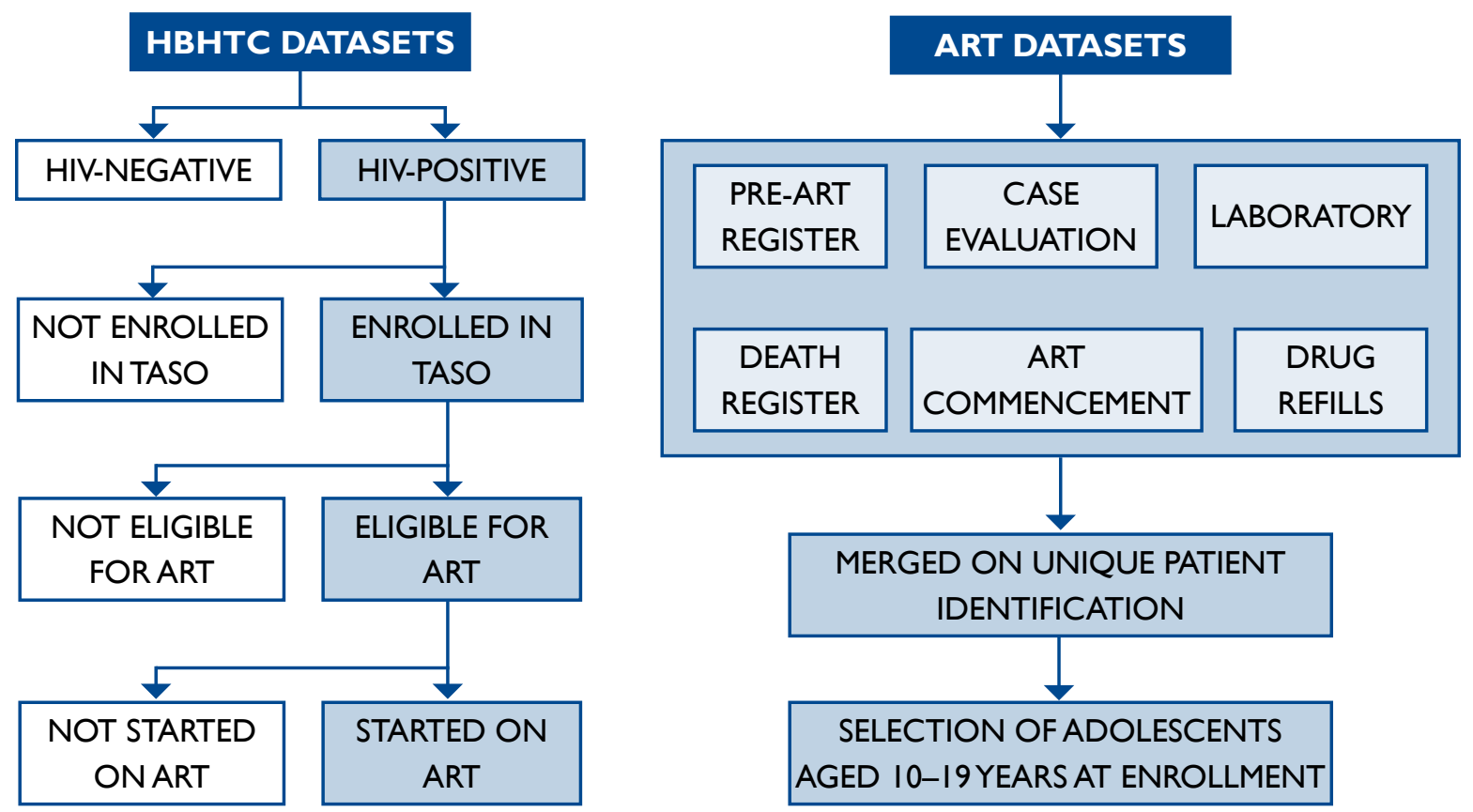




\section{REVIEW OF DOCUMENTS}

The review of policy and program documents as well as the extraction and merging of clinical datasets took place from 4-15 November 2013. The policy and program documents were obtained from TASO and Uganda's Ministry of Health. We undertook a review of the existing HIV and AIDS treatment, care, and support program documents in Uganda (such as national policy guidelines on service provision and training manuals for service providers) to determine the contextual factors that might facilitate or influence enrollment into HIV care, initiation of treatment, and retention in treatment programs among adolescents living with HIV. The results of the review are presented in the appendix.

\section{EXTRACTION OF CLINICAL DATASETS}

The HBHTC and ART datasets were obtained from 11 TASO centers. The HBHTC datasets included all individuals who were counseled and tested for HIV under the program regardless of whether they were later enrolled in TASO programs. The ART datasets, on the other hand, comprised all individuals who were enrolled in TASO programs regardless of where they were counseled and tested for HIV. The ART datasets were extracted from the following records: Pre-ART Registry, Case Evaluation, ART Commencement, Deaths, Monitoring Refills, and Laboratory (Figure 1). A cohort of adolescent clients aged 10-19 years who were initiated on ART between January 2006 and December 2011 at TASO clinics were included in the analysis. TASO collects information on date of testing, date of enrollment in care and support programs, date of confirmation of eligibility for antiretroviral drugs (ARVs), date of commencement of ARVs, and dates of drug refills since the client was started on ARVs. The ART datasets for the various components of HIV care, treatment, and support including registration, determination of eligibility for ART, and commencement and adherence to treatment from all the eleven centers are stored in separate files in Access format at TASO headquarters and include all age groups. However, each file contains unique client identifier numbers that were used to merge information pertaining to the same client from the different datasets.

\section{DATA ANALYSIS}

Analysis involved both descriptive statistics and multivariate Cox regression analysis. Descriptive analysis entailed reviewing the cascade of HIV care, treatment, and support services under the HBHTC program as well as estimating the level of retention in TASO ART programs. The review of the cascade of care was conducted for adolescents aged 10-19 years and adults aged 20 years and above. Analysis entailed simple frequencies to determine the proportions of adolescents and adults that: (i) tested positive among those who received HBHTC since 2005; (ii) were enrolled in care and support programs at TASO centers among those who tested positive during HBHTC; (iii) were determined to be eligible for ART among those who were enrolled in care and support programs at TASO centers; and (iv) were started on ART among those who were determined to be eligible. The purpose of the analysis was to determine whether the proportions of adolescents were significantly different from those of adults at each stage in the cascade. Significance tests of proportions were conducted to determine whether the differences between the two groups were statistically significant.

With respect to the level of retention, the percentage of patients with HIV known to be on treatment 6 and 12 months after initiation of ART and at yearly intervals thereafter (e.g., 24, 36, 48 months) is recommended as a core indicator for documenting program retention over time (Tassie et al. 2010). It is 
generated per calendar year by selecting all patients starting ART during a given year (denominator) and reporting those who are still alive and on ART at a specific time point (numerator) - that is, excluding those who were known to have died, stopped ART, or were lost to follow-up (Tassie et al. 2010). We calculated retention rate as the proportion of patients who were enrolled in TASO centers and alive (including those who transferred to non-TASO centers) at the end of each observation period at 6,12 , 24,36 , and 48 months. We further examined whether the level of retention at each observation period differed among adolescents initiating treatment in each successive year from 2006 to 2010, which could give an indication of the changing programmatic contexts.

Multivariate analysis was conducted to determine the sociodemographic and clinical factors associated with program attrition at 12,24 , and 36 months. ${ }^{1}$ The analysis involved estimation of three separate Cox proportional hazard models for each of the time periods with exposure defined from the time of enrollment in the ART program to the end of analysis period (i.e., at 12, 24, and 36 months). The incidence rates of subcategories of attrition (dead, lost to follow-up [LTFU], and treatment stopped) were expressed as the number of patients with at least one occurrence of the given event per 100 person years. A two-tailed statistical test with a p-value of $<0.05$ was considered to be statistically significant. Baseline characteristics included patient's sociodemographics such as age (10-14 and 15-19 years), sex (male and female), and religious affiliation (Anglican, Catholic, Muslim, and Protestant); available measures of disease severity including CD 4 count $(<100$ cells/ $\mu \mathrm{l}, 100-249$ cells $/ \mu \mathrm{l}$, and 250 or more cells/ $\mu \mathrm{l})$ and WHO clinical staging (Stage $1 \& 2$ and Stage 3\&4); adherence level ( $<75$ percent, 75 percent-95 percent, and greater than 95 percent); and mode of ART delivery (community drug distribution points [CDDP] and health facility). Adherence level was determined by the frequency of taking drugs based on a threeday recall and pharmacy records within a given quarter. Patients were defined as LTFU if their last patient contact was more than three months before the end date of the observation period and were considered to have been lost to follow up at their last contact date. The results are presented as adjusted hazard ratios (AHR) with 95 percent confidence intervals (CI).

\section{ETHICAL CONSIDERATIONS}

The study obtained ethical approval from the Population Council Institutional Review Board, TASO Institutional Review Committee and the Uganda National Council for Science and Technology (UNCST). In addition, no personal identifiers such as names, addresses, or contact information of clients were included in the extracted clinical data. Rather, a unique patient identification number was used to merge the datasets from the various records.

${ }^{1}$ At 48 months, the model could not converge because of missing data. 


\section{KEY FINDINGS}

\section{CHARACTERISTICS OF ADOLESCENTS}

Table 1 presents the distribution of adolescents who were enrolled in TASO programs during the period. The majority of the adolescents were female (63 percent), reflecting the generally higher HIV prevalence among women (8 percent) than men (6 percent) in the country (Ministry of Health et al. 2012).

More than half ( 55 percent) of the adolescents were aged 10-14 years while 75 percent had primary level education. Most of the adolescents (73 percent) had CD4 counts of 100 and above at the time of initiating ART, while 91 percent had adherence level above 95 percent. One-quarter ( 25 percent) of the adolescents were sexually active (had ever had sex) suggesting that the majority were born with HIV. Most of the adolescents (62 percent) obtained their drug refills from a health facility (Table 1). 
Table I Distribution of adolescents aged I 0-19 years in TASO ART programs by background characteristics at the time of enrollment, 2006-20 I I

\begin{tabular}{|c|c|c|}
\hline Characteristics & Percent & $\begin{array}{l}\text { Number of } \\
\text { adolescents }\end{array}$ \\
\hline \multicolumn{3}{|l|}{ Sex of client } \\
\hline Female & 63.2 & 390 \\
\hline Male & 36.8 & 227 \\
\hline \multicolumn{3}{|l|}{ Age (years) } \\
\hline $\mid 0-11$ & 26.6 & 164 \\
\hline $12-14$ & 29.2 & 180 \\
\hline $15-17$ & 22.8 & 141 \\
\hline $18-19$ & 21.4 & 132 \\
\hline \multicolumn{3}{|c|}{ Highest level of education completed } \\
\hline None/pre-primary & 7.3 & 45 \\
\hline Primary & 75.0 & 461 \\
\hline Senior $1-4$ & 15.9 & 98 \\
\hline Senior 5 and above & 1.8 & 11 \\
\hline \multicolumn{3}{|l|}{ Religion } \\
\hline Anglican & 36.0 & 221 \\
\hline Catholic & 42.4 & 260 \\
\hline Muslim & 10.6 & 65 \\
\hline Pentecostal & 7.8 & 48 \\
\hline Seventh Day Adventist & I.I & 7 \\
\hline Other & 2.1 & 13 \\
\hline \multicolumn{3}{|l|}{ Venue of ARV refill } \\
\hline CDDP & 36.3 & 224 \\
\hline Health facility & 62.1 & 383 \\
\hline Home/other & 1.6 & 10 \\
\hline \multicolumn{3}{|l|}{ CD4 at ART initiation } \\
\hline$<100$ cells $/ \mu \mid$ & 27.0 & 154 \\
\hline 100-249 cells/ $\mu \mathrm{l}$ & 37.0 & 211 \\
\hline 250 or more cells/ $\mu \mathrm{l}$ & 36.0 & 205 \\
\hline \multicolumn{3}{|l|}{ WHO clinical staging } \\
\hline Stage I \& 2 & 71.5 & 436 \\
\hline Stage $3 \& 4$ & 28.5 & 174 \\
\hline \multicolumn{3}{|c|}{ Sexually active (ever had sex) } \\
\hline Yes & 24.6 & 143 \\
\hline No & 75.4 & 139 \\
\hline
\end{tabular}




\section{CASCADE OF CARE UNDER HBHTC PROGRAM}

Between 2005 and 2011, TASO tested a total of 77,881 clients through the HBHTC program. Out of these, 28 percent were adolescents aged 10-19 years and 43 percent were adults aged 20 years and above. Table 2 presents the numbers of adolescents and adults that went through the cascade of the TASO HBHTC program during the period.

Table 2 Number of adolescents $10-19$ years and adults 20 years and above who received various HIV services through the TASO HBHTC program, 2005-20 I I

\begin{tabular}{|lrrrrr|} 
Year & $\begin{array}{c}\text { Number } \\
\text { tested }\end{array}$ & $\begin{array}{c}\text { Number } \\
\text { positive }\end{array}$ & $\begin{array}{c}\text { Number } \\
\text { enrolled }\end{array}$ & $\begin{array}{c}\text { Number } \\
\text { eligible for } \\
\text { ART }\end{array}$ & $\begin{array}{r}\text { Number } \\
\text { initiated } \\
\text { on ART }\end{array}$ \\
\hline Adolescents 10-19 years & & & & & \\
2005 & 675 & 33 & 3 & 1 & 1 \\
2006 & 4,447 & 126 & 40 & 6 & 5 \\
2007 & 3,833 & 73 & 29 & 7 & 5 \\
2008 & 2,966 & 64 & 26 & 9 & 9 \\
2009 & 4,318 & 68 & 21 & 6 & 6 \\
2010 & 5,076 & 79 & 16 & 6 & 5 \\
2011 & 774 & 18 & 5 & 2 & 2 \\
Total & 22,089 & 461 & 140 & 37 & 33 \\
Adults 20 years and above & & & & & \\
2005 & 732 & 104 & 22 & 6 & 6 \\
2006 & 5,214 & 557 & 179 & 29 & 28 \\
2007 & 5,336 & 656 & 213 & 76 & 72 \\
2008 & 3,782 & 529 & 161 & 57 & 52 \\
2009 & 7,570 & 794 & 127 & 38 & 34 \\
2010 & 9,079 & 920 & 203 & 61 & 57 \\
2011 & 1,426 & 178 & 29 & 10 & 8 \\
Total & 33,139 & 3,738 & 934 & 277 & 257 \\
\hline
\end{tabular}

Overall, 8 percent of adolescents and adults tested through the program were HIV-positive (2 percent of adolescents and 11 percent of adults; Figure 2). As expected the proportion of adolescents who tested positive was consistently lower than that of adults across the years $(\mathrm{p}<0.01$ in all cases). Over time, the proportion of adolescents that tested positive under the program declined by more than half from 5 percent in 2005 to 2 percent in 2011. However, the proportion of adults aged 20 years and above that tested positive under the program fluctuated between 10 percent and 14 percent (Figure 2). 
Figure 2 Percentage of adolescents $10-19$ years and adults 20 years and above who were HIV-positive among those tested through the TASO HBHTC program, 2005-20I I

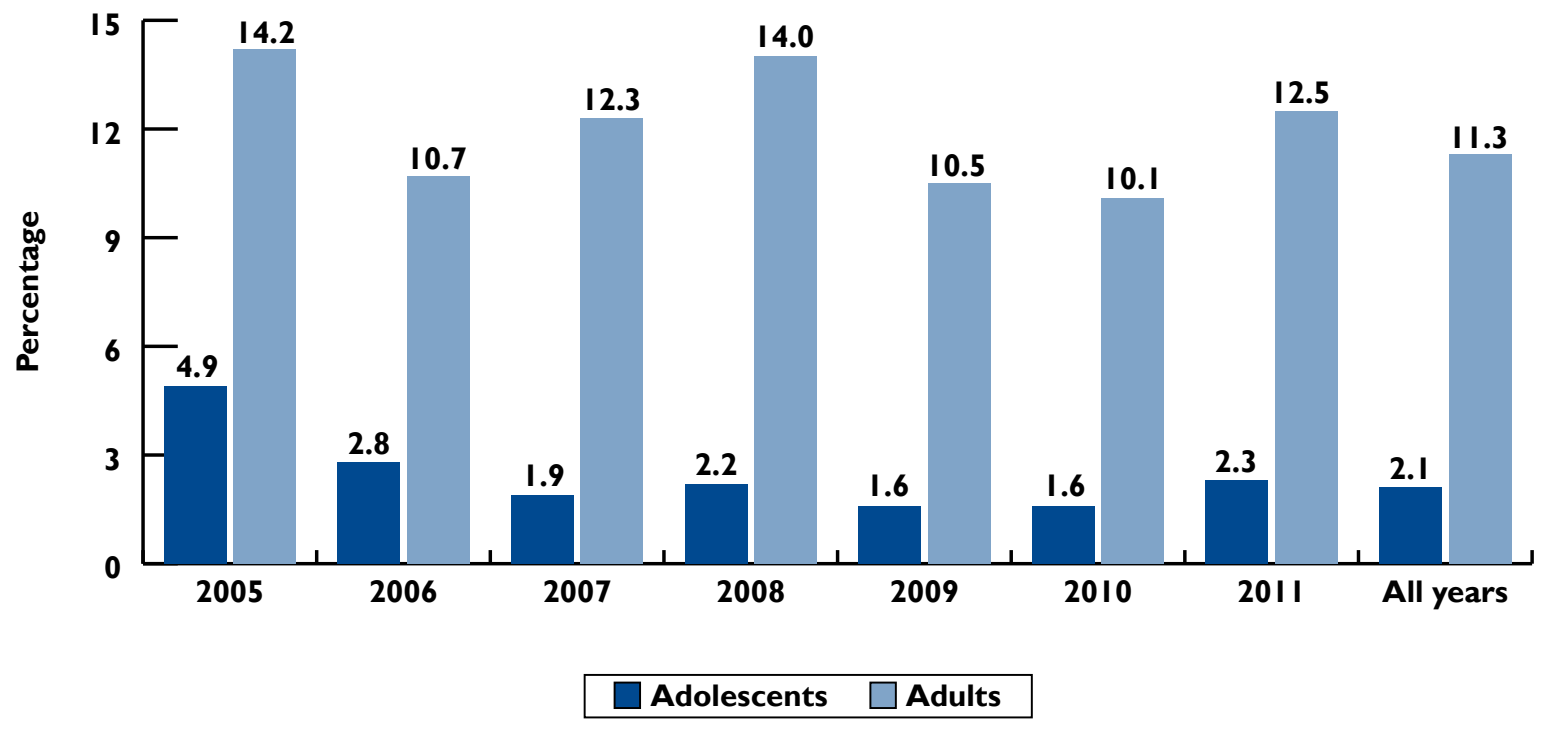

Under the HBHTC program, the proportion of HIV-positive adolescents that were enrolled in TASO centers more than tripled from 9 percent in 2005 to 32 percent in 2006 and steadily increased to 40 percent and 41 percent in 2007 and 2008 respectively (Figure 3). Nonetheless, the proportion of HIVpositive adolescents that were enrolled in TASO programs declined to 31 percent and 20 percent in 2009 and 2010 respectively. By contrast, the proportion of HIV-positive adults that were enrolled in TASO centers increased by 11 percentage points between 2005 and 2006 (from 21 percent to 32 percent) before levelling off at 33 percent in 2007. In addition, the proportion of adults that were enrolled in TASO programs declined to 30 percent and 16 percent in 2008 and 2009 respectively (Figure 3). It is also worth noting that during the first year of the program, a higher proportion of HIV-positive adults than adolescents were enrolled in TASO centers. However, in 2006, a similar proportion of HIV-positive adults and adolescents were enrolled in TASO programs while between 2007 and 2009, a higher proportion of HIV-positive adolescents compared to adults were enrolled in the centers. 
Figure 3 Percentage of adolescents $10-19$ years and adults 20 years and above who were enrolled in TASO centers among those who tested positive through the HBHTC program, 2005-20 I I

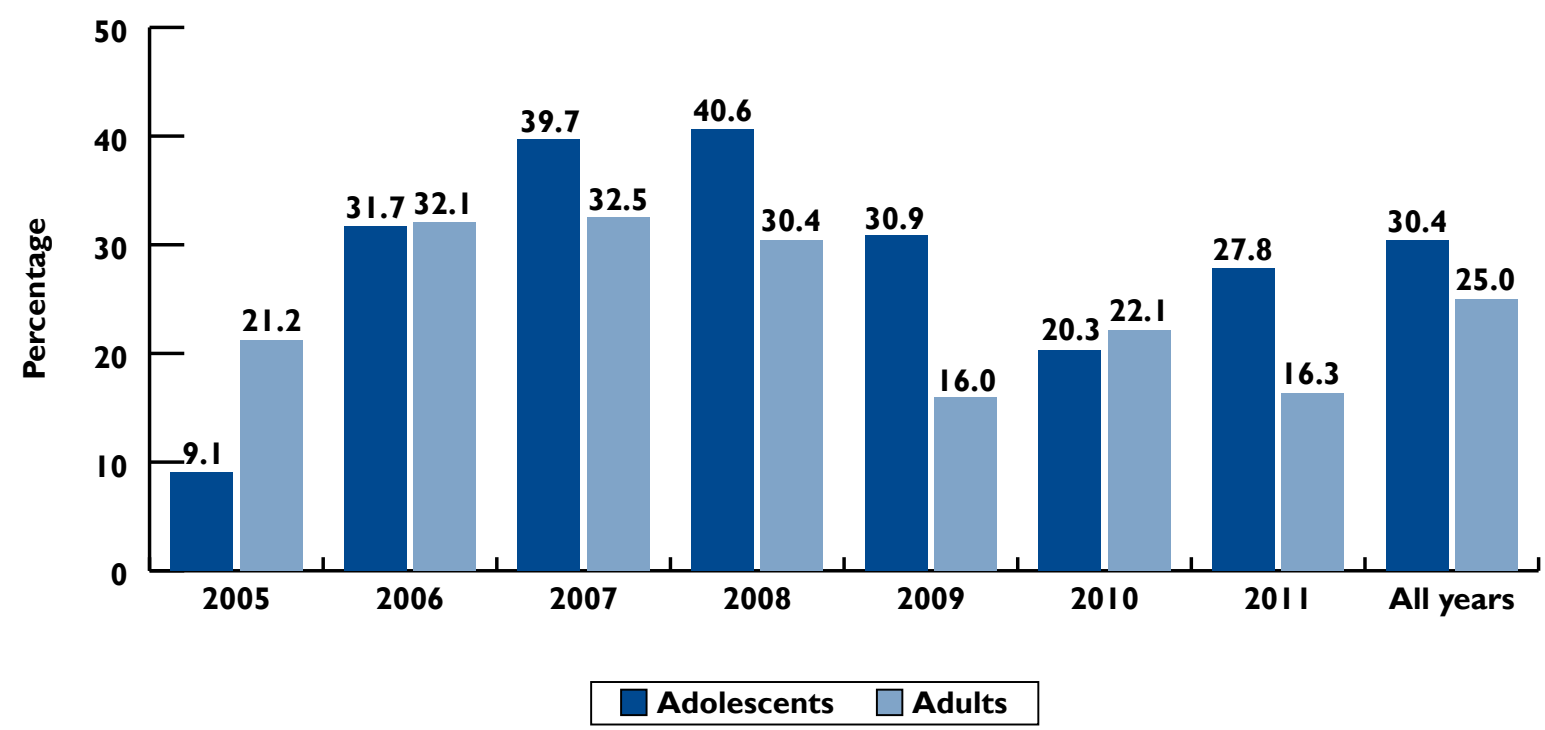

Figure 4 presents the distribution of adolescents 10-19 years and adults aged 20 years and above who were eligible for ART among those who were enrolled in TASO programs between 2005 and 2011. With the exception of a slight decline in 2009, the proportion of adolescents who were found to be eligible for ART more than doubled from 15 percent in 2006 to 40 percent in 2011. Over the same period, the proportion of adults aged 20 years who were found to be eligible for ART more than doubled between 2006 and 2007 (from 16 percent to 36 percent) but fluctuated between 30 percent and 35 percent thereafter (Figure 4). Among those who were eligible for treatment between 2005 and 2011, 89 percent of adolescents and 93 percent of adults were initiated on TASO ART programs. 
Figure 4 Percentage of adolescents $10-19$ years and adults 20 years and above who were eligible for ART among those enrolled in TASO centers through the HBHTC program, 2005-20I I

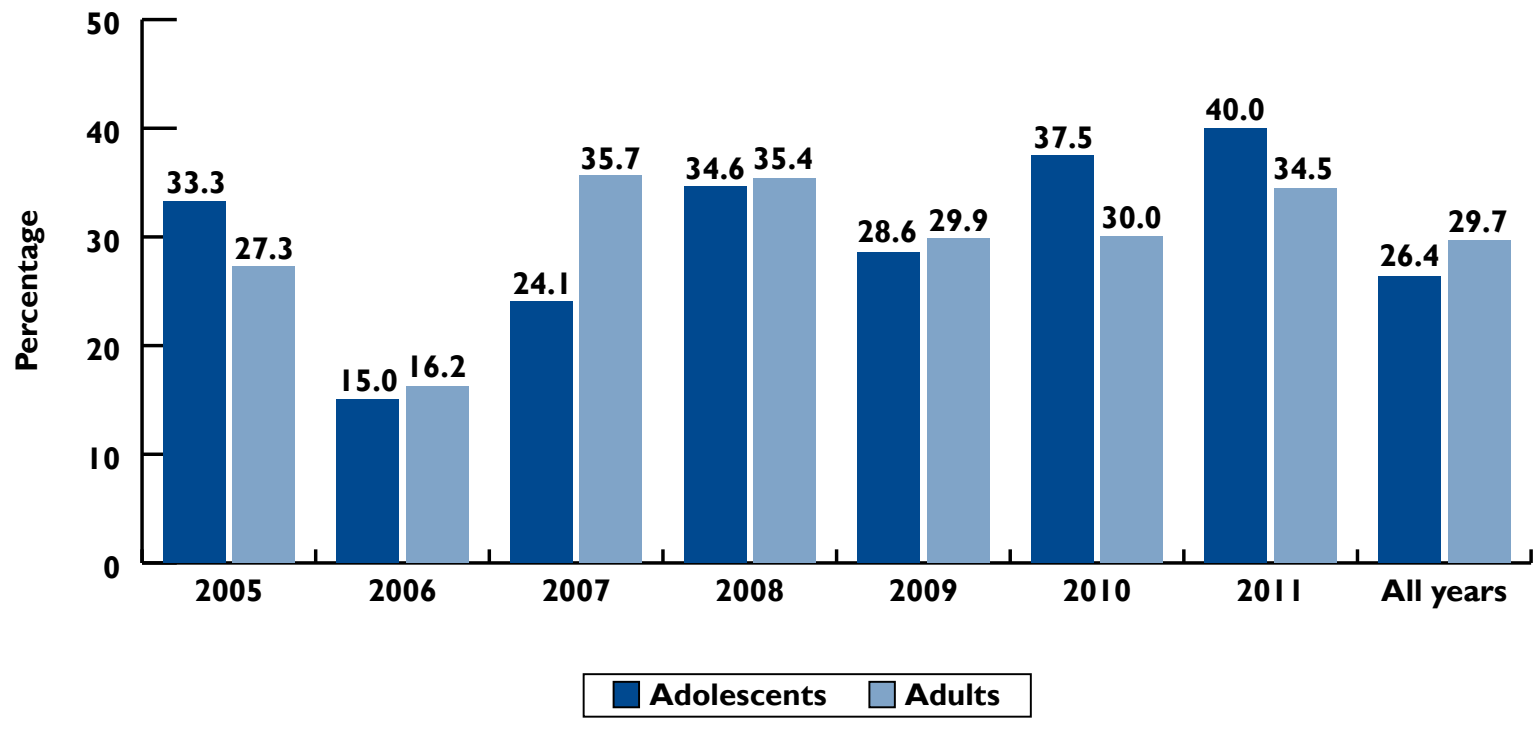

\section{LEVEL OF RETENTION OF ADOLESCENTS IN ART PROGRAMS}

Out of the 617 HIV-positive adolescents included in the study, 78 percent were still in TASO programs and 6 percent had died, while 15 percent were lost to follow up during the review period. As expected, the level of retention of adolescents declined with longer duration of stay in TASO ART programs. The overall level of retention of adolescents in the programs was 96 percent at 6 months, 90 percent at 12 months, 83 percent at 24 months, 76 percent at 36 months, and 71 percent at 48 months (Figure 5).

Figure 5 Overall level of retention of adolescents I 0-19 years in TASO ART programs, 2006-20II

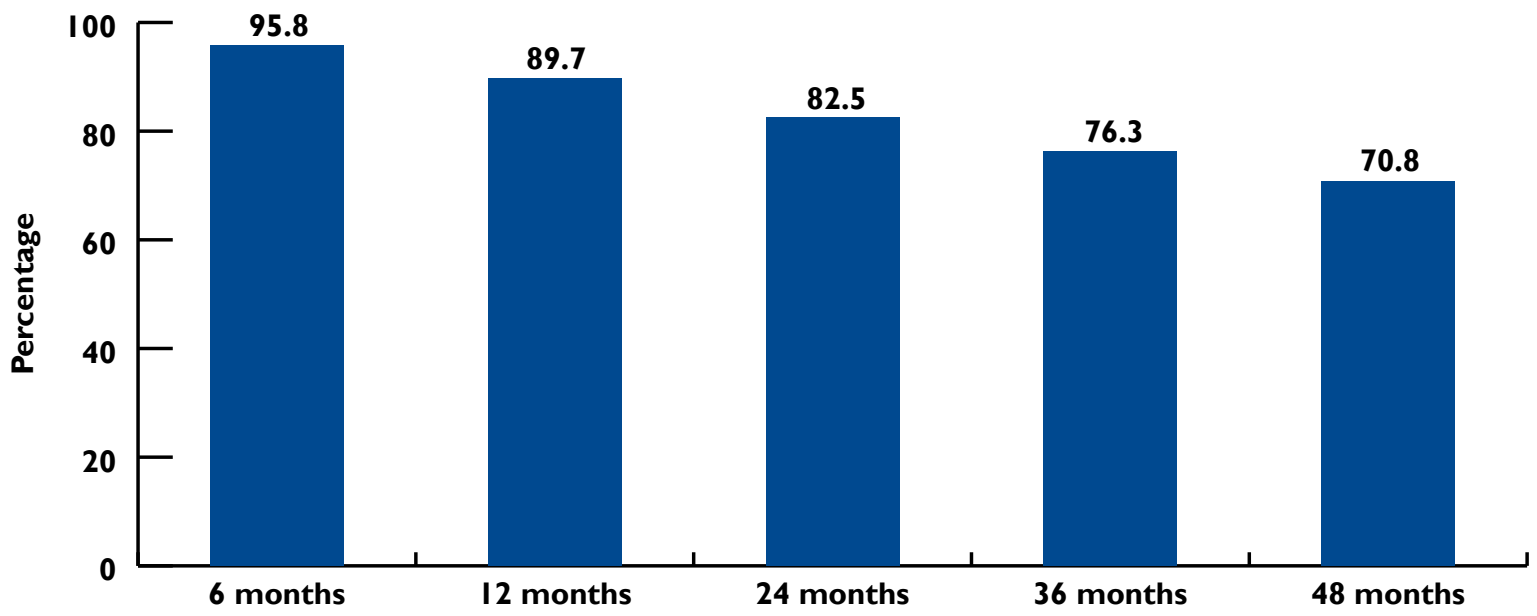




\section{TRENDS IN RETENTION OF ADOLESCENTS IN ART PROGRAMS}

Figure 6 presents the level of retention of various cohorts of adolescents in TASO ART programs. There is little variation in the level of retention between different cohorts at 6 months (ranges from 93 percent for the 2010 cohort to 100 percent for the 2006 cohort). At 12 months, however, there were wide variations in the level of retention especially between the 2010 cohort and the other cohorts (79 percent for the 2010 cohort and over 90 percent for the 2006, 2007, 2008, and 2009 cohorts). The gaps in the level of retention between cohorts of adolescents further widen as the duration increases to 24, 36, and 48 months, with the level of retention of later cohorts of adolescents being lower than that of earlier cohorts (Figure 6).

Figure 6 Trends in retention of various cohorts of adolescents 10-19 years in TASO ART programs, 2006-20 I I

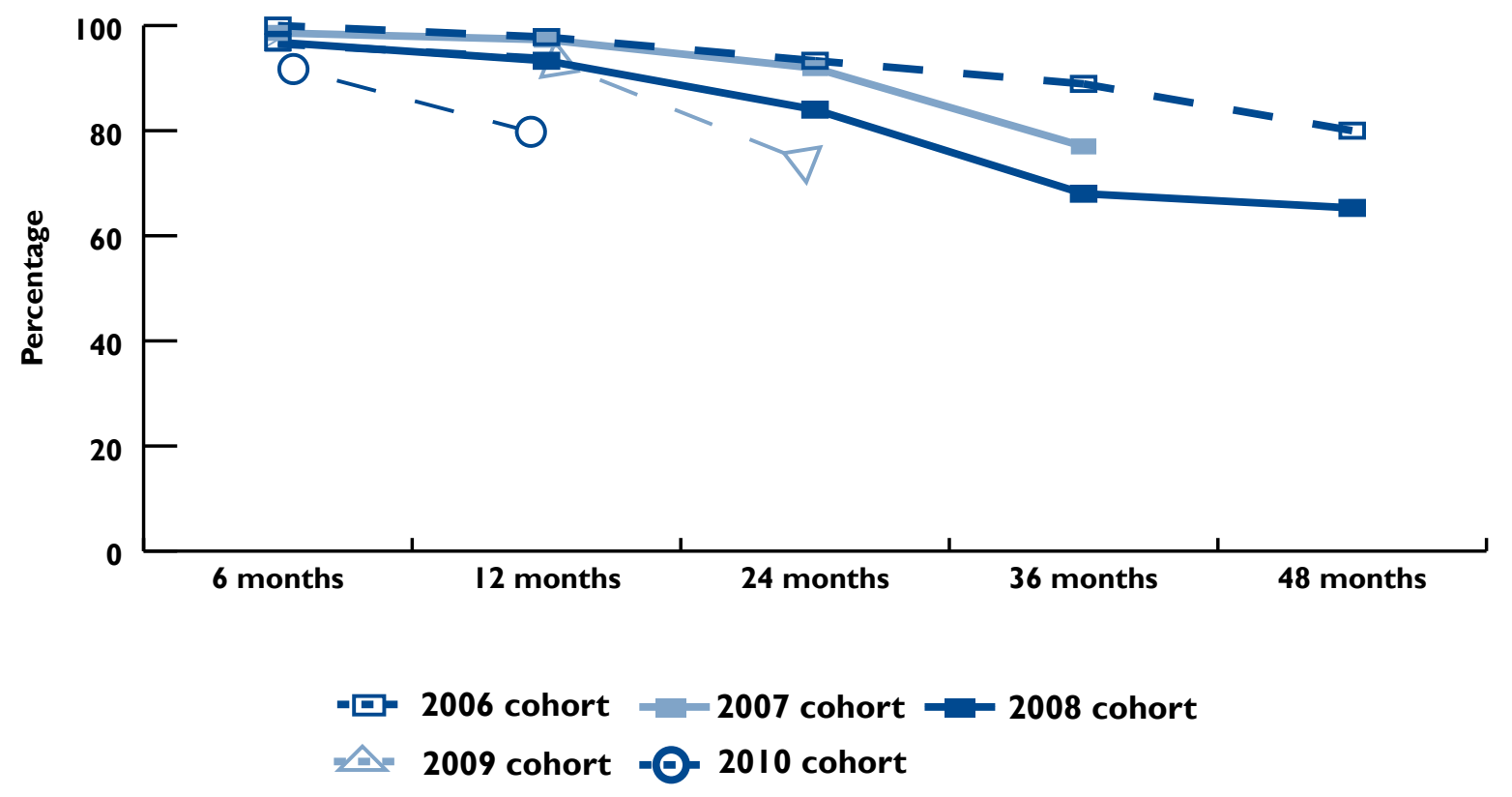

\section{FACTORS ASSOCIATED WITH NON-RETENTION OF ADOLESCENTS IN ART PROGRAMS}

The results of the multivariate analysis predicting non-retention of adolescents aged 10-19 years in TASO ART programs at various time points are presented in Table 3. The risk of non-retention in ART programs was significantly greater among adolescents who obtained their ARV refills from a health facility than among those who obtained the refills from CDDP at all the time points considered (i.e., 12, 24, and 36 months). In particular, the risk of non-retention was greater by 2.58 times at 12 months (95\% CI: $1.26,5.29), 1.59$ times at 24 months (95\% CI: 1.23, 2.05), and 1.31 times at 36 months (95\% CI: 1.05 , 1.61; Table 2) among adolescents who obtained their ARV refills from a health facility compared to those who obtained the refills from CDDP. It is also worth noting that the magnitude of the differences in the risk of non-retention in care by mode of ARV delivery reduced with time. 
The results in Table 3 further show that at 24 and 36 months, the risk of non-retention in care was significantly greater (by between 1.33 and 1.41 times) among adolescents with higher compared to those with lower CD4 count at the time of ART initiation. There was, however, no significant difference in the risk of non-retention in care by the level of CD4 count at 12 months (Table 3). By contrast, there was significant difference in the risk of non-retention in care by WHO clinical staging at 12 months but not at 24 and 36 months. At 12 months, the risk of non-retention in care was 2.21 times greater among adolescents at stage 3 and 4 than among those at stage 1 and 2 at the time of initiating ART.

With respect to age, the risk of non-retention in care was significantly greater among older (15-19 years) than among younger (10-14 years) adolescents during the first two years following ART initiation. The risk of non-retention was 1.88 times greater at 12 months (95\% CI: 1.01, 3.48) and 1.30 times greater at 24 months (95\% CI: 1.02, 1.66) among older compared to younger adolescents. However, by the third year, there was no significant difference in the risk of non-retention between older and younger adolescents. The results also show that with longer duration of observation, the risk of non-retention in care was significantly lower among male than among female adolescents. The risk was lower by 0.68 times at 24 months $(95 \%$ CI: $0.52,0.88)$ and by 0.79 times at 36 months $(95 \%$ CI: $0.64,0.98)$ among male compared to female adolescents. There was, however, no significant difference in the risk of non-retention in care by sex of the adolescent at 12 months. 
Table 3 Hazard ratios from multivariate analysis predicting non-retention of adolescents aged I0-19 years in TASO ART programs at various time points, 2006-20 I I

\begin{tabular}{|c|c|c|c|}
\hline Covariate & $\begin{array}{l}12 \text { months } \\
\text { AHR }(95 \% \mathrm{CI})\end{array}$ & $\begin{array}{l}24 \text { months } \\
\text { AHR (95\% CI) }\end{array}$ & $\begin{array}{c}36 \text { months } \\
\text { AHR }(95 \% \mathrm{CI})\end{array}$ \\
\hline \multicolumn{4}{|l|}{ Sex of client (ref: Male) } \\
\hline Female & $\begin{array}{c}1.09 \\
(0.59,2.02)\end{array}$ & $\begin{array}{c}0.68 * * \\
(0.52,0.88)\end{array}$ & $\begin{array}{c}0.79 * \\
(0.64,0.98)\end{array}$ \\
\hline \multicolumn{4}{|l|}{ Age of client (ref: I0-14 years) } \\
\hline $15-19$ years & $\begin{array}{c}1.88^{*} \\
(1.01,3.48)\end{array}$ & $\begin{array}{c}1.30 * \\
(1.02,1.66)\end{array}$ & $\begin{array}{c}|.2| \\
(0.98,1.49)\end{array}$ \\
\hline \multicolumn{4}{|l|}{ Religion (ref:Anglican) } \\
\hline Catholic & $\begin{array}{c}1.05 \\
(0.53,2.10)\end{array}$ & $\begin{array}{c}1.15 \\
(0.88,1.52)\end{array}$ & $\begin{array}{c}1.16 \\
(0.92,1.46)\end{array}$ \\
\hline Muslim & $\begin{array}{c}0.63 \\
(0.18,2.20)\end{array}$ & $\begin{array}{c}0.88 \\
(0.55,1.38)\end{array}$ & $\begin{array}{c}0.92 \\
(0.62,1.33)\end{array}$ \\
\hline Protestant & $\begin{array}{c}1.65 \\
(0.69,3.92)\end{array}$ & $\begin{array}{c}1.14 \\
(0.77,1.70)\end{array}$ & $\begin{array}{c}1.19 \\
(0.85,1.67)\end{array}$ \\
\hline \multicolumn{4}{|c|}{ Mode of ARV delivery (ref: CDDP) } \\
\hline Health facility & $\begin{array}{c}2.58^{* *} \\
1.26,5.29)\end{array}$ & $\begin{array}{c}1.59 * * \\
(1.23,2.05)\end{array}$ & $\begin{array}{c}1.3 I^{*} \\
(1.05,1.61)\end{array}$ \\
\hline \multicolumn{4}{|l|}{$\begin{array}{l}\text { WHO clinical staging at ART } \\
\text { initiation (ref: Stage I \& 2) }\end{array}$} \\
\hline Stage $3 \& 4$ & $\begin{array}{c}2.21^{*} \\
(1.19,4.09)\end{array}$ & $\begin{array}{c}0.99 \\
(0.75,1.31)\end{array}$ & $\begin{array}{c}0.94 \\
(0.74,1.18)\end{array}$ \\
\hline \multicolumn{4}{|l|}{$\begin{array}{l}\text { CD4 at ART initiation } \\
\text { (ref: }<100 \text { cells/ } / \mu l)\end{array}$} \\
\hline $100-249$ cells $/ \mu \mid$ & $\begin{array}{c}1.13 \\
(0.58,2.20)\end{array}$ & $\begin{array}{c}1.38^{*} \\
(1.01,1.90)\end{array}$ & $\begin{array}{c}1.36^{*} \\
(1.05,1.77)\end{array}$ \\
\hline$\geq 250$ cells $/ \mu \mathrm{l}$ & $\begin{array}{c}0.48 \\
(0.20,1.13)\end{array}$ & $\begin{array}{c}1.41^{*} \\
(1.02,1.96)\end{array}$ & $\begin{array}{c}1.33^{*} \\
(1.02,1.75)\end{array}$ \\
\hline \multicolumn{4}{|c|}{ Adherence level (ref: <75\%; poor) } \\
\hline 75\%-95\% (Fair) & $\begin{array}{c}0.31 \\
(0.05,2.05)\end{array}$ & $\begin{array}{c}2.09 \\
(0.48,9.03)\end{array}$ & $\begin{array}{c}1.32 \\
(0.46,3.83)\end{array}$ \\
\hline$>95 \%$ (Good) & $\begin{array}{c}0.38 \\
(0.08,1.68)\end{array}$ & $\begin{array}{c}1.84 \\
(0.45,7.55)\end{array}$ & $\begin{array}{c}1.20 \\
(0.44,3.27)\end{array}$ \\
\hline Person-years of observation & $\mathrm{I}, 3 \mid \mathrm{I} .5863$ & $1,311.5863$ & $1,3 \mid 1.5863$ \\
\hline Number of persons & 528 & 528 & 528 \\
\hline
\end{tabular}

Notes:Adherence level was determined by the frequency of taking drugs based on a three-day recall and pharmacy records within a given quarter; ref: reference category; ${ }^{*} p<0.05 ;{ }^{*} \mathrm{p}<0.01$. 


\section{CONCLUSIONS AND RECOMMENDATIONS}

\section{DISCUSSION}

The key findings of the study are that: 1) the overall level of retention of adolescents in TASO programs is comparable with those of adults in existing studies, although there were variations in the retention of various cohorts of adolescents especially from 12 months onwards; 2) the risk of non-retention of adolescents in TASO care programs was significantly greater among those who obtained their ARV refills from a health facility than among those who obtained the refills from community drug distribution points at all the time points considered (12,24 and 36 months); the risk of non-retention was significantly greater among adolescents at WHO clinical stage 3 and 4 than among those at stage 1 and 2 at the time of initiating ART (at 12 months); 3) the risk of non-retention in TASO care was significantly greater among older (15-19 years) than among younger (10-14 years) adolescents (at 12 and 24 months) as well as among adolescents with higher than among those with lower CD4 count at the time of initiating ART (at 24 and 36 months); 4) the risk of non-retention in care was significantly lower among male compared to female adolescents with longer duration of observation (at 24 and 36 months); and 5) the proportion of HIV-positive adolescents that were tested under the HBHTC program and who were enrolled in TASO centers more than quadrupled between 2005 and 2008 before declining by about half between 2008 and 2010.

The HIV and AIDS policy environment in Uganda is favorable for implementing interventions including testing, counseling, treatment, and support programs for various population groups. However, effective implementation of programs has been hampered by inadequate and inconsistent messaging, limited human and financial resources to meet the demand for services, and lack of efficient management of funds and supplies, as well as weak linkage and referral systems (Ministry of Health 2011; Uganda AIDS Commission, n.d.). In addition, HIV-positive adolescents aged 10-19 years face challenges associated with adherence to treatment and program retention as they transition from pediatric to adult care (Foster and Fidler 2010). There are, however, no clear policy or programmatic actions aimed at reducing the potential drop-out from care among adolescents during the transition from pediatric to adult care that is evident from the review of policy and program documents. There is therefore need for clear policies and concrete programs that address retention of HIV-positive adolescents in ART programs as they transition from pediatric to adult care in the country.

Long-term retention of clients in ART programs is considered a major challenge for HIV programs in sub-Saharan Africa (Harries et al. 2010). Studies show that although retention of clients in ART programs in the region is more than 90 percent at 6 months, it declines with time ranging between 80 and 90 percent at 12 months, 70 and 80 percent at 24 months, and 60 and 70 percent at 36 months (Geng et al. 2011; Fox and Rosen 2010; Tayler-Smith et al. 2010). In Uganda, it was estimated that as of 2011, 84 percent of clients were still on ART after 12 months of initiation (Republic of Uganda 2012). Although the programmatic challenges are likely to affect the level of retention of adolescents in ART 
programs, the findings of this study show that the overall retention of adolescents in TASO programs is comparable with those of adults in existing studies (Geng et al. 2011; Fox and Rosen 2010; Ministry of Health 2011; Republic of Uganda 2012; Tayler-Smith et al. 2010). However, there were variations in the level of retention of various cohorts of adolescents especially from 12 months onwards. Specifically, retention decreased at each time period among adolescents initiating ART in each successive year since 2006 and the gaps widened with longer duration of observation. Whereas this could be an indication of the changing program context (such as availability of funding, expansion of clinics leading to clients transferring from TASO to new clinics, and changing treatment guidelines over the period), the design of the study did not allow for exploring the specific reasons for the variations in the levels of retention of adolescents by the year of initiating ART. It is, however, worth noting that the high levels of retention of adolescents in TASO treatment programs could be due to the intensive resources geared toward targeting whole families with HIV testing, counseling, treatment, and support services. Thus, although resources for targeting whole families may not always be available, the programs provide valuable lessons for improving access to treatment services among HIV-positive adolescents.

The second important finding of this study is that the risk of non-retention of adolescents in TASO care programs was significantly greater among those who obtained their ARV refills from a health facility than among those who obtained the refills from community drug distribution points at all the time points considered (12, 24, and 36 months). In addition, at 12 months, the risk of non-retention in care was significantly greater among adolescents at WHO clinical stage 3 and 4 than among those at stage 1 and 2 at the time of initiating ART. The findings suggest that community-based ART distribution initiatives and early diagnosis of HIV infection do improve the chances of retaining adolescents in ART programs. Community-based initiatives have been found to increase the uptake of HIV services in sub-Saharan Africa (Matovu and Makumbi 2007). Early initiation of ART has, on the other hand, been associated with decreasing trends in AIDS-related mortality in the country (Ministry of Health 2011). Variations in the risk of non-retention in the TASO treatment programs by venue of drug refills could be due to the fact that most HIV-positive adolescents with high levels of adherence receive drugs from community drug distribution points while the less adherent ones receive drugs from health facilities. Nonetheless, a crosstabulation of adherence level and venue of drug refill showed that there was no significant association between the two attributes, suggesting that counseling and close monitoring might have improved adherence among clients who received drug refills from facilities.

The third key finding of the study is that the risk of non-retention in TASO care was significantly greater among older (15-19 years) than among younger (10-14 years) adolescents at 12 and 24 months. In addition, at 24 and 36 months, the risk of non-retention in care was significantly greater among adolescents with higher than among those with lower CD4 count at the time of initiating ART. The higher risk of non-retention among older compared to younger adolescents could be due to challenges associated with transitioning from pediatric to adult care, given that ages 15-19 years also mark transition to adulthood. Differences in retention by CD4 count could be due to the fact that adolescents with higher CD4 count at the time of initiating ART may presume that they are healthy and might therefore not feel the need to continue with treatment.

Available evidence indicates that women have better health-seeking behavior than men and that those who are living with HIV are likely to initiate treatment earlier than men (Braitstein et al. 2008). Contrary to this expectation, the results of the study show that the risk of non-retention in care was significantly 
lower among male compared to female adolescents with longer duration of observation (at 24 and 36 months). However, given that the study was based on secondary data, it was not possible to explore further the reasons for lower risk of non-retention in care among male compared to female adolescents.

With respect to HBHTC, the program contributed to increasing proportions of adolescents aged 10-19 years being enrolled in TASO care centers during the first four years of its operation. In particular, the proportion of HIV-positive adolescents who were enrolled in TASO centers more than quadrupled between 2005 and 2008. However, the proportion of adolescents enrolled in TASO care centers under the program declined by about half between 2008 and 2010. The initial success of the program and the subsequent decline in the proportions of adolescents being in enrolled in care could partly reflect the interplay between a supportive policy environment and the challenges associated with program implementation in the country including the availability of adequate resources (Ministry of Health 2011; Uganda AIDS Commission, n.d.). The overall proportions of adolescents who were tested through the program and enrolled in TASO care centers also remained low across the years. This could largely be due to the fact that although clients accepted being counseled and tested at home by TASO, it was not a pre-condition that they had to enroll in TASO care centers. Rather, they might have chosen to enroll for services elsewhere, which was entirely within their rights.

\section{CONCLUSION}

Although the level of retention of adolescents aged 10-19 years in TASO care centers is comparable to those of existing studies among adults, significant variations exist at various time points by cohort, age, sex, mode of ART delivery, WHO clinical staging, and CD4 count at the time of initiating treatment. However, the findings show that community drug distribution points do improve retention of adolescents in HIV care and treatment programs. Nonetheless, given the potential for selection bias, more research is needed to determine whether the approach should be used to specifically target those at high risk of dropping out of care and treatment programs.

\section{RECOMMENDATIONS}

- HIV care, treatment, and support programs in Uganda should strengthen such strategies as community drug distribution points, which have the potential of improving retention of adolescents in care and treatment, to specifically target those who are at high risk of dropping out.

- Since the issue of retaining older adolescents in HIV care and treatment programs could partly be associated with challenges with transition from pediatric to adult care, more research is needed to determine whether setting up transition units to cater for those who receive services from health facilities but are not comfortable with obtaining services from pediatric or adult clinics could improve retention.

- Further research involving collection of primary quantitative and qualitative data is needed to determine why later cohorts of adolescents had lower levels of retention in care compared to earlier cohorts and why male adolescents had significantly lower risk of non-retention in care compared to their female counterparts. 


\section{REFERENCES}

AIC [AIDS Information Centre]. 2013. "Night HIV counseling and testing: A strategic option for high-risk urban and per-urban populations.” Available at: http://www.aicug.org/index.php/en/10-homepage/36-night-hiv-counseling-and-testing [Accessed on May 24, 2013].

Birungi, H. et al. 2011. "Sexual and reproductive health needs of adolescents living with HIV in Kenya." Nairobi: APHIA II OR Project in Kenya/Population Council.

Birungi, H. et al. 2009. "Preventive service needs of young people perinatally infected with HIV in Uganda," AIDS Care 21(6): 725-731.

Birungi, H. et al. 2008. "Sexual and reproductive health needs of adolescents perinatally infected with HIV in Uganda," FRONTIERS Final Report. Washington, DC: Population Council.

Braitstein, P. et al. 2008. "Gender and the use of anti-retroviral treatment in resource-constrained settings: Findings from a multicenter collaboration," Journal of Women's Health 17(1): 47-55.

Foster, C. and S. Fidler. 2010. "Optimizing antiretroviral therapy in adolescents with perinatally acquired HIV-1 infection." Expert Review of Anti-infective Therapy 8(12): 1403-1416.

Fox, M.P. and S. Rosen. 2010. "Patient retention in antiretroviral therapy programs up to three years on treatment in subSaharan Africa, 2007-2009: systematic review," Tropical Medicine and International Health 15(Suppl 1): 1-15.

Garbus, L. and E. Marseille. 2003. "HIV/AIDS in Uganda." San Francisco: AIDS Policy Research Center, University of California.

Geng, E.H. 2012. "Improving retention in HIV care in resource-limited settings." Available at: www.medscape.com. Accessed on January 10, 2013.

Geng, E.H. et al. 2011. "Retention in care and connection to care among HIV-infected patients on antiretroviral therapy in Africa: Estimation via a sampling-based approach,” PLoS One 6(7): e21797.

Genuis, S.J. and S.K. Genuis. 2005. "HIV/AIDS prevention in Uganda: Why has it worked?” Postgraduate Medical Journal 81(960): 615-617.

Giodarno, T.P. 2012. "How should we measure retention in HIV care?" Available at: www.medscape.com. Accessed on January $10,2013$.

Giordano, T. et al. 2007. "Retention in care: A challenge to survival with HIV infection," Clinical Infectious Diseases 44: 1493-1499.

Green, E.C. et al. 2006. "Uganda HIV prevention success: The role of sexual behavior change and the national response," AIDS and Behavior 10(4): 335-346.

Harding, R. et al. 2009. "PEPFAR Public Health Evaluation—care and support—phase I, Uganda." Chapel Hill, USA and London, UK: Measure Evaluation and King's College.

Harries, A.D. et al. 2010. "Strategies to improve patient retention on antiretroviral therapy in sub-Saharan Africa," Tropical Medicine and International Health 15(Suppl 1):70-75.

Hindin, M.J. and A.O. Fatusi. 2009. "Adolescent sexual and reproductive health in developing countries: An overview of trends and interventions," International Perspectives in Sexual and Reproductive Health 35(2): 58-62.

Kajja, V. 2013. Provider-initiated HIV counseling and testing—The Ugandan case. Available at: http://e.itg.be/ihp/?p=6086

[Accessed on May 24, 2013]. 
Matovu, Joseph K.B. and Fredrick E. Makumbi. 2007. "Expanding access to voluntary HIV counseling and testing in subSaharan Africa: Alternative approaches for improving uptake, 2001-2007," Tropical Medicine \& International Health 12(11): $1315-1322$.

Menzies, N. et al. 2009. "The costs and effectiveness of four HIV counseling and testing strategies in Uganda," AIDS 23(3): 395-401.

Ministry of Health (MOH) [Uganda], ICF International, Centers for Disease Control and Prevention (CDC), United States Agency for International Development (USAID), and World Health Organization (WHO). 2012. Uganda AIDS Indicator Survey 2011. Kampala, Uganda and Calverton, MD: MOH, ICF International, CDC, USAID, and WHO.

Ministry of Health [Uganda]. 2011. Temporal Trends in Baseline Characteristics and Antiretroviral Therapy Outcomes among Clients Initiating Antiretroviral Therapy in Uganda, 2005-2010. Kampala/Ministry of Health, Republic of Uganda.

Ministry of Health [Uganda]. 2010a. Uganda HIV Counselling and Testing Policy. $3^{\text {rd }}$ edition. Kampala: Ministry of Health, Republic of Uganda.

Ministry of Health [Uganda]. 2010b. National Implementation Guidelines for HIV Counselling and Testing in Uganda. Kampala: Ministry of Health, Republic of Uganda..

Ministry of Health [Uganda]. 2010c. Health Sector Strategic Plan III, 2010/11-2014/15. Kampala: Ministry of Health, Republic of Uganda.

Ministry of Health [Uganda]. 2009a. National Antiretroviral Treatment Guidelines for Adults, Adolescents and Children. $3^{\text {rd }}$ Edition. Kampala: Ministry of Health, Republic of Uganda..

Ministry of Health [Uganda]. 2009b. National Couples HIV Counseling and Testing Communication Strategy. Kampala: Ministry of Health, Republic of Uganda.

Ministry of Health [Uganda] and ORC Macro. 2006. Uganda HIVIAIDS Serobehavioural Survey 2004-2005. Calverton, Maryland, USA: Ministry of Health \& ORC Macro.

Ministry of Health [Uganda]. 2005. Uganda National Policy Guidelines for HIV Counselling and Testing. Kampala: Ministry of Health, Republic of Uganda.

Ministry of Health [Uganda]. 2003a. Antiretroviral Treatment Policy for Uganda. Kampala: Ministry of Health, Republic of Uganda.

Ministry of Health [Uganda]. 2003b. Policy for Reduction of the Mother-to-Child HIV Transmission in Uganda. Kampala: Ministry of Health, Republic of Uganda.

Ministry of Health [Uganda]. 1999. National Health Policy. Kampala: Ministry of Health, Republic of Uganda.

Ministry of Justice [Uganda]. 2014. The Anti-Homosexuality Act, 2014. Kampala: Ministry of Justice, Republic of Uganda.

Okware, A. et al. 2005. "Revisiting the ABC strategy: HIV prevention in Uganda in the era of antiretroviral therapy,"

Postgraduate Medical Journal 81(960): 625-628.

Onyango, S. and M. Magoni. 2002. "Implementing PMTCT program in Uganda: Challenges and lessons learned," proceeding of the XIV International AIDS Conference, Barcelona.

Republic of Uganda. 2012. Global AIDS Response Progress Report: Country Progress Report, Uganda. Kampala: Uganda AIDS Commission.

Republic of Uganda. 2011. National Strategic Plan for HIV హ́AIDS, 2011/12-2014/15. Kampala: Republic of Uganda.

Republic of Uganda. (n.d.). Nutritional Care and Support for People Living with HIVIAIDS in Uganda: Guidelines for Service Providers. Kampala: Republic of Uganda.

Semugoma, P., C. Beyrer, and S. Baral. 2012. "Assessing the effects of anti-homosexuality legislation in Uganda on HIV prevention, treatment, and care services," SAHARA J 9(3): 173-176. 
Serwadda, D. et al. 1985. "Slim disease: A new disease in Uganda and its association with HTLV-III infection," Lancet 2(8460): 849-852.

Tassie, J.M. et al. 2010. "Trends in retention on antiretroviral therapy in national programs in low-income and middle-income countries," Journal of Acquired Immune Deficiency Syndromes 54(4): 437-41. doi:10.1097/QAI.0b013e3181d73e1b.

Tayler-Smith K., R. Zachariah, and M. Massaquoi. 2010. "Unacceptable attrition among WHO stages 1 and 2 patients in a hospital-based setting in rural Malawi: can we retain such patients within the general health system?," Trans R Soc Trop Med Hyg 104: 313-319.

Uganda AIDS Commission. 2007. Moving Toward Universal Access: National HIV \& AIDS Strategic Plan 2007/8 - 2011/12.

Kampala: Uganda AIDS Commission, Republic of Uganda.

Uganda AIDS Commission. 2000. The National Strategic Framework for HIVIAIDS Activities in Uganda, 2000/1-2005/6. Kampala: Uganda AIDS Commission, Republic of Uganda.

Uganda AIDS Commission. (n.d.). Status if HIV \& AIDS Prevention, Care and Treatment in Uganda. Kampala: Uganda AIDS Commission, Republic of Uganda.

UNAIDS [Joint United Nations Programme on HIV/AIDS]. 2012. UNAIDS Report on the Global HIVIAIDS Epidemic 2012. Geneva: UNAIDS.

UNAIDS [Joint United Nations Programme on HIV/AIDS]. 2011. UNAIDS Data Tables 2011. Geneva: UNAIDS.

UNAIDS [Joint United Nations Programme on HIV/AIDS]. 2010a. UNAIDS Report on the Global HIVIAIDS Epidemic 2010. Geneva: UNAIDS.

UNAIDS [Joint United Nations Programme on HIV/AIDS]. 2010b. Combination HIV Prevention: Tailoring and Coordinating Biomedical, Behavioural and Structural Strategies to Reduce New HIV Infections. Geneva: UNAIDS.

Wanyenze, R.K. et al. 2008. "Acceptability of routine HIV counselling and testing, and HIV seroprevalence in Ugandan hospitals," Bulletin of the World Health Organization 86(4): 302-309.

WHO [World Health Organization]. 2006. Antiretroviral Drugs for Treating Pregnant Women and Preventing HIV Infection in Infants: Towards Universal Access: Recommendations for a Public Health Approach. Geneva: WHO.

WHO [World Health Organization]. 2012. Retention in HIV Programmes: Defining Challenges and Identifying Solutions. Geneva: WHO.

WHO [World Health Organization] and UNFPA [United Nations Fund for Population Activities]. 2006. Sexual and Reproductive Health of Women Living with HIVIAIDS: Guidelines on Care, Treatment and Support for Women Living with HIVI AIDS and Their Children in Resource-constrained Settings. Geneva: WHO.

WHO [World Health Organization], UNAIDS [Joint United Nations Programme on HIV/AIDS], and UNICEF [United Nations Children's Fund]. 2010. Towards Universal Access: Scaling Up Priority Interventions in the Health Sector. Geneva: WHO, UNAIDS and UNICEF.

WHO [World Health Organization], UNAIDS [Joint United Nations Programme on HIV/AIDS], and UNICEF [United Nations Children's Fund]. 2009. Towards Universal Access: Scaling Up Priority Interventions in the Health Sector. Geneva: WHO, UNAIDS and UNICEF. 


\section{APPENDIX: DOCUMENT REVIEW}

\section{POLICY CONTEXT}

\section{Infrastructure}

The first AIDS case was diagnosed in Uganda in 1982 and by 1986, the disease had reached the level of a generalized epidemic predominantly transmitted through heterosexual contact (Ministry of Health and ORC Macro 2006; Serwadda et al. 1985). In response, the Ugandan government (the Government) established the AIDS Control Programme in the Ministry of Health in 1986 to carry out epidemiological surveillance of the epidemic; ensure safe supply of blood for transfusion; and provide information, education, and communication (IEC) as well as patient care and counseling services (Uganda AIDS Commission 2000). The Government adopted a multi-sectoral approach in dealing with the epidemic in 1990/1991. The Uganda AIDS Commission was created in 1992 to coordinate the multi-sectoral response encompassing HIV prevention, counseling, testing, care, and support services involving public, private, civil society, and community-based organizations (Ministry of Health and ORC Macro 2006).

\section{HIV prevention policy}

In 1999, the Government issued the National Health Policy with one of its priorities being the prevention and control of HIV. This was to be achieved through information, education, and communication (IEC) campaigns; HIV counseling and testing; promotion of condom use; treatment of sexually transmitted infections (STIs); reduction of mother-to-child transmission; provision of palliative care; and promotion of community involvement in the care of patients with AIDS (Ministry of Health 1999). In 2000, the Government unveiled the National Strategic Framework for AIDS Activities in the country for the period 2001-2006 focusing on promotion of abstinence, faithfulness, and condom use (ABC); reducing mother-to-child transmission of HIV as well as providing care and support to households affected by the epidemic (Uganda AIDS Commission 2000). At the expiration of the National Strategic Framework, the Government developed a new strategic plan in 2007, the National HIV \& AIDS Strategic Plan 2007-2012, which had goals to reduce the incidence of HIV and AIDS by 40 percent and to expand care, treatment, and support interventions to 80 percent of those in need by the year 2012 (Uganda AIDS Commission 2007). In addition, the policies and strategic plans recognized the importance of addressing underlying factors that constrain HIV prevention such as harmful sociocultural and gender norms, inequitable access to services, gender-based violence, and stigma and discrimination (Ministry of Health 1999; Uganda AIDS Commission 2000, 2007).

\section{HIV testing and counseling policy}

The Government issued the first Voluntary Counseling and Testing (VCT) Policy in 2002, which had the goal of ensuring access to high-quality VCT services for all people in Uganda (Ministry of Health 2010a, 
2010b). The policy was revised in 2005 to HIV Counselling and Testing Policy in order to encompass new models of testing including provider-initiated testing and counseling (PITC) and HBHTC (Ministry of Health 2005, 2010a, 2010b). The policy was again revised in 2010 to take into account emerging issues such as key populations, special groups including children and persons with disabilities, quality assurance, safe medical circumcision, and ethical and legal issues around HIV counseling and testing (Ministry of Health 2010a). The Government further issued the National Implementation Guidelines for HIV Counselling and Testing in the country at the same time to guide the implementation of the HIV Counselling and Testing Policy (Ministry of Health 2010b).

\section{HIV treatment, care and support policy}

With respect to treatment, care and support services, the Government developed the Antiretroviral Treatment Policy for Uganda in 2003, with objectives to: (1) standardize the provision of ART and related services to adults and children; (2) build capacity of healthcare workers to provide ART in a safe, effective, and integrated manner; and (3) ensure uninterrupted supply of antiretroviral (ARV) drugs, laboratory reagents, and medical supplies (Ministry of Health 2003a). The Government further issued the Policy for Reduction of the Mother-to-Child HIV Transmission in Uganda in the same year. The objective of this policy was to guide the provision of ART for prevention of mother-to-child transmission (PMTCT) of HIV and reduce pediatric HIV cases (Ministry of Health 2003b). In 2009, the Government unveiled revised ART guidelines for adults, adolescents, and children to take into account the 2006 revision of WHO global ART recommendations (Ministry of Health 2009a; WHO 2006). Improving access to quality HIV treatment and care services was also a key focus of the third Health Sector Strategic Plan for the period 2010-2015 and the National Strategic Plan for HIV \& AIDS for the period 2011-2015 (Ministry of Health 2010c; Republic of Uganda 2011).

One of the Government's policy goals is to mitigate the health and socio-economic effects of HIV and AIDS on individuals, households, and communities in Uganda (Uganda AIDS Commission 2000). Besides treatment, nutritional support is one strategy that the Government has outlined for mitigating the health impact of the epidemic. To this end, the Government issued guidelines for service providers on nutritional care and support for people living with HIV in the country (Republic of Uganda, n.d.). In addition, the Health Sector Strategic Plan III for the period 2010-2015 emphasized incorporating nutritional support into the management and treatment of HIV and AIDS (Ministry of Health 2010c). Other care and support strategies that the Government has outlined in various policy documents include: (1) promoting palliative care and social and spiritual support for children infected and affected by HIV and AIDS; (2) providing psychosocial, financial, and material support (shelter, food, school fees) to AIDS orphans, child-headed households, and guardians/foster families; (3) promoting home-based care for people living with HIV; (4) developing income-generating projects with skills development components and training family members in the management and monitoring of the projects; and (5) identifying non-governmental organizations (NGOs) and micro-financing institutions to extend credit to the families most affected by HIV and AIDS (Uganda AIDS Commission 2000, 2007; Ministry of Health 2003). 


\section{PROGRAMMATIC CONTEXT}

\section{IEC/BCC campaigns}

The first AIDS control program was set up in Uganda in 1987 with an emphasis on the ABC approach to HIV prevention (Genuis and Genuis 2005; Green et al. 2006; Ministry of Health and ORC Macro 2006). The approach involved IEC/behavior change communication (BCC) campaigns using various channels including mass media (print materials, radio, and billboards), community mobilization, and interpersonal communications (Green et al. 2006). The campaigns targeted the general population as well as specific groups such as youth, female sex workers and their clients, traders, fishermen, soldiers, long distance drivers, bar girls, police, and students (Green et al. 2006). The messages focused not only on $\mathrm{ABC}$ but also cross-generational sex as well as modes of HIV transmission (Green et al. 2006). The campaigns have been carried out throughout the country by the Government as well as faith-based, civil society, and community-based organizations (Green et al. 2006; Okware et al. 2005).

\section{HIV counseling and testing services}

The ABC prevention strategy was later expanded to include HIV counseling and testing (HCT), PMTCT, ART, and HIV care and support services - a strategy also known as ABC Plus (Ministry of Health and ORC Macro 2006). The country employs various HCT models including routine HIV counseling and testing for pregnant women (sentinel surveillance), VCT or client-initiated counseling and testing (CICT), PITC, HBHTC, couples HIV counseling and testing (CHCT), mobile HIV testing, and moonlight (night-time) testing for high-risk groups such as sex workers (Ministry of Health 2005; Republic of Uganda 2011). The sentinel surveillance system was established in 1985 in Kampala before being rolled out to other sites in 1989 (Garbus and Marseille 2003). Between 1989 and end of 2001, the number of sentinel sites increased from six located in a few places in and outside Kampala to 20 sites spread throughout the country but mostly in urban and peri-urban clinics (Garbus and Marseille 2003).

VCT was first launched in the country in 1990 with the establishment of the AIDS Information Center (AIC) in Kampala and by 2002, AIC had 70 sites in 34 districts (Garbus and Marseille 2003; Menzies et al. 2009; Ministry of Health 2010a). The Ministry of Health started a voluntary door-to-door HIV counseling and testing program in 1999 (Menzies et al. 2009; Wanyeze et al. 2008). The Ministry further launched the national couples HIV counseling and testing in the same year under the campaign 'Go Together, Know Together' (Ministry of Health 2009b). In addition, the Government began rolling out PITC in 2013 after initial piloting of the strategy in regional referral hospitals (Kajja 2013). Moonlight HIV counseling and testing was, on the other hand, first piloted by AIC in Arua district in 2007 before being rolled out to other districts (AIC 2013). Thus, HCT services have been expanded in all districts in the country with the national guidelines allowing for provision of the services in health facilities (public, private, faith-based, and NGO), community settings (e.g., stand-alone sites, home or workplace), and in special circumstances such as surveillance or research settings (Ministry of Health 2010b). By 2011, HCT services were available in all hospitals and Health Center Level IV, 80 percent of Health Center Level III, and 22 percent of Health Center Level II facilities (Republic of Uganda 2012). Estimates from the 2011 Uganda AIDS Indicator Survey show that 60 percent of adults aged 15-49 years had ever been tested for HIV (Ministry of Health et al. 2012). 


\section{Treatment services}

The Ministry of Health began offering free PMTCT services in 2000 (WHO et al. 2009). However, by 2005, the proportion of HIV-positive mothers receiving PMTCT services was only 12 percent (WHO et al. 2009). By 2010, 1,150 health facilities were providing PMTCT services in the country including all public and private hospitals and Health Center Level IV, 90 percent of Health Center Level III, and 10 percent Health Center Level II facilities (Republic of Uganda 2012). Over the same period, the proportion of HIV-positive mothers receiving PMTCT services in the country increased to 53 percent (WHO et al. 2010). Since the Government launched universal access to free antiretroviral drugs in 2004, a total of 409 public and private facilities had been accredited to provide ART by the end of December 2008 , and, of the 357,000 people estimated to need treatment, about 168,000 were already accessing ART countrywide (Ministry of Health 2009). By 2011, it was estimated that 58 percent of adults and children in need of ART were accessing the services (Republic of Uganda 2012).

\section{Care and support services}

With respect to care and support, efforts by the government, private sector, and civil society organizations (CSOs) have focused on alleviating the impact of HIV and AIDS on people living with HIV, orphans and vulnerable children (OVC), and affected households and communities (Republic of Uganda 2012). A 2009 evaluation of forms of care available at sampled health facilities in the country found that the most common components were adherence counseling, nutritional advice, family planning counseling, preand post-HIV test counseling, treatment for diarrhea, and treatment for skin rash (Harding et al. 2009). Other forms of care and support include psychosocial support services especially for OVC, including life skills, counseling and guidance, formal education, and vocational training (Harding et al. 2009; Republic of Uganda 2012). The universal primary and secondary education initiatives by the government have, for instance, led to continued increase in the number of OVC in primary and secondary schools in the country (Republic of Uganda 2012). In addition, some CSOs have interventions addressing household food insecurity and malnutrition while the government's Social Assistance Grants for Empowerment (SAGE) program initiated in 2010 aims to provide social protection to poor households (Republic of Uganda 2012).

\section{SUMMARY AND IMPLICATIONS}

In summary, the HIV and AIDS policy environment in Uganda is favorable for implementing interventions including testing, counseling, treatment, and support programs for various population groups. The policies have also been consistently updated in line with national and international developments regarding the epidemic. For instance, the revised National Strategic Plan for HIV\&AIDS for the period 2011-2015 took into account the principles of combination prevention, which has been defined as "rights-based, evidence-informed, and community-owned programmes that use a mix of biomedical, behavioral, and structural interventions, prioritized to meet the current HIV prevention needs of particular individuals and communities, so as to have the greatest sustained impact on reducing new infections" (Republic of Uganda 2011; UNAIDS 2010b:8). In particular, the policies promote evidence-based interventions such as HIV counseling and testing, PMTCT, safe medical circumcision, ART, and condom use as well as behavioral and structural interventions including IEC/BCC, STI treatment, and medical infection control (Republic of Uganda 2011). The policies further outline measures for comprehensive social support protection for individuals, households, and communities to 
enable them to prevent, manage, and overcome risks and vulnerabilities associated with the epidemic. It is, however, worth noting that some policies, such as the Anti-Homosexuality Act of 2014 (Ministry of Justice 2014), remain unfavorable for programs that target key populations such as men who have sex with men (Semugoma et al. 2012). There is also no clear policy that addresses retention of HIV-positive adolescents on ART as they transition from pediatric to adult care.

In spite of the remarkable progress in HIV and AIDS programming in the country, challenges remain. For example, there have been inconsistencies in the IEC messages about the effectiveness of the various elements of the $\mathrm{ABC}$ strategy (A, B, and $\mathrm{C}$ ) in changing behavior (Uganda AIDS Commission, n.d.). In addition, the IEC/BCC messages have largely been based on mass media campaigns rather than interpersonal communication (Uganda AIDS Commission, n.d.). There also has been limited emphasis on prevention counseling for individuals who test HIV-negative in order to remain uninfected (Uganda AIDS Commission, n.d.). Effective provision of HCT, PMTCT, and ART services is, on the other hand, hampered by limited human and financial resources to meet the demand, lack of efficient management of funds and supplies, and weak linkage and referral systems (Onyango and Magoni 2002; Republic of Uganda 2012). Budget constraints have also limited the country's ability to address the needs and demands of people living with HIV, orphans, and affected households and communities (Republic of Uganda 2012). HIV-positive adolescents also face challenges associated with adherence to treatment and program retention as they transition from pediatric to adult care (Foster and Fidler 2010). These challenges may negatively impact the level of retention of adolescents in care, treatment and support programs in the country. 

U.S. Agency for International Development I 300 Pennsylvania Avenue, NW

Washington, DC 20523

Tel: (202) 7I2-0000

Fax: (202) 216-3524

www.usaid.gov 